\title{
Motoneuron Resistance to Apoptotic Cell Death In Vivo Correlates with the Ratio between X-Linked Inhibitor of Apoptosis Proteins (XIAPs) and Its Inhibitor, XIAP-Associated Factor 1
}

\author{
Daniel Perrelet, ${ }^{1}$ Florence E. Perrin, ${ }^{1}$ Peter Liston, ${ }^{2,4}$ Robert G. Korneluk, ${ }^{2,4}$ Alex MacKenzie, ${ }^{3}$ Marcel Ferrer-Alcon, ${ }^{1}$ \\ and Ann C. Kato ${ }^{1}$ \\ ${ }^{1}$ Division of Clinical Neuromuscular Research and Department of Anesthésiologie, Pharmacologie et Soins Intensifs de Chirurgie, Faculty of Medicine, \\ Centre Médical Universitaire, 1211 Geneva 4, Switzerland, ${ }^{2}$ Molecular Genetics Research Laboratory and ${ }^{3}$ Molecular Genetics Research Institute, Children's \\ Hospital of Eastern Ontario, Ottawa, Ontario K1H8L1, Canada, and ${ }^{4}$ Aegera Therapeutics Inc., Ottawa, Ontario K1H8L1, Canada
}

\begin{abstract}
Apoptotic cell death occurs in motoneurons in the neonate but not in the adult after a lesion of a peripheral nerve. To investigate the molecular basis for this difference, we have analyzed the expression and localization of inhibitors of apoptosis proteins (IAPs) and their inhibitors X-linked IAP (XIAP)-associated factor 1 (XAF1), Smac/DIABLO, and Omi/HtrA2 in motoneurons at both ages. Quantitative immunohistochemical and immunoblotting analysis of these proteins in motoneurons revealed an increase in IAP expression [XIAP, neuronal apoptosis inhibitory protein, human IAP1 (HIAP1), and HIAP2] during postnatal development as opposed to XAF1, which decreased during the same period; there was no significant alteration in either Smac/DIABO or Omi/HtrA2. The regulation of IAPs and XAF1 varied after axotomy of the sciatic nerve; in the neonate, there was a significant loss of IAP in the injured motoneurons as opposed to the adult, in which there was only a moderate decrease. By overexpressing exogenous IAPs in neonatal axotomized motoneurons, it was possible to delay motoneuron cell death (Perrelet et al., 2000, 2002). In opposition, the overexpression of exogenous XAF1 in adult motoneurons totally abrogated the natural resistance of these cells to axotomy. The degradation in the adult, induced by XAF1, could be overcome by simultaneously expressing high levels of exogenous XIAP in adult motoneurons. These experiments suggest that it may be the ratio between XAF1 and XIAP that confers the resistance of adult motoneurons to axotomy. In addition, the regulation in the levels of IAPs and XAF1 may be essential in the cell death mechanism of injured motoneurons.
\end{abstract}

Key words: motoneurons; axotomy; IAPs; XAF1; apoptosis; rat

\section{Introduction}

One of the confounding problems in the field of apoptotic neuronal cell death concerns the ability of adult motoneurons to survive after a lesion of a peripheral nerve as opposed to neonatal motoneurons, which undergo a rapid demise (Elliott and Snider, 1996). Because motoneurons degenerate in various human diseases, it is important to understand the molecular mechanisms that are responsible for the cell death process and also to identify the genetic influence that confers cellular protection. The experimental paradigm of peripheral nerve axotomy offers an ideal model for studying motoneuron cell death in the spinal cord.

The differential sensitivity of neonatal and adult motoneu-

Received July 22, 2003; revised March 1, 2004; accepted March 1, 2004.

This work was supported by the Association Françaises Contre les Myopathies (France), the Carlos and Elsie de Reuter Foundation (Switzerland), the Fondation Novartis, the Swiss National Science Foundation, and the Swiss Foundation for Neuromuscular Diseases. We thank Beatrice King for excellent technical assistance and Anna Ferri, Fabienne de Bilbao, Jean-Claude Martinou, and Yannick Simonin for reading this manuscript.

Correspondence should be addressed to Ann C. Kato, Division of Clinical Neuromuscular Research and Department of Anesthésiologie, Pharmacologie et Soins Intensifs de Chirurgie, Centre Médical Universitaire, 1 rue Michel Servet, 1211 Geneva 4, Switzerland. E-mail: ann.kato@medecine.unige.ch.

D01:10.1523/JNEUROSCI.0413-04.2004

Copyright $\odot 2004$ Society for Neuroscience $\quad$ 0270-6474/04/243777-09\$15.00/0 rons to axotomy could result from programmed cell death occurring during development. From embryonic day 13 to postnatal day 3, $\sim 65 \%$ of all motoneurons degenerate by an apoptotic mechanism (Oppenheim, 1991; Yamamoto and Henderson, 1999). It is believed that these neurons die because of their inability to compete for a limiting supply of neurotrophic factor (Oppenheim, 1991). This predisposition of embryonic and neonatal motoneurons to die during development suggests that they have a greater sensitivity to cell death as opposed to adult motoneurons, which are capable of resisting an apoptotic stimulus.

In neonatal animals, transected motoneurons die by an apoptotic mechanism, as evidenced by caspase-3 activation and DNA fragmentation (de Bilbao and Dubois-Dauphin, 1996; Li et al., 1998b; de Bilbao et al., 1999; Guarin et al., 1999; Vanderluit et al., 2000). Motoneuron cell death in the neonate can be prevented by the overexpression of the antiapoptosis proteins bcl-2 and bcl-xl (Dubois-Dauphin et al., 1994; Parsadanian et al., 1998) or by the deletion of the proapoptotic protein Bax (Deckwerth et al., 1996). In adult animals, the axotomy of a peripheral nerve leads to the upregulation of a number of genes involved in axonal regeneration such as cytoskeletal elements, growth-associated proteins, and trophic factor receptors (Elliott and Snider, 1996). However, 
the identification of essential genes involved in adult motoneuron survival after injury has been unsuccessful.

We have previously shown that the family of endogenous human inhibitors of apoptosis proteins (IAPs) can also protect neonatal motoneurons from axotomy (Perrelet et al., 2000, 2002). Human IAP proteins such as neuronal apoptosis inhibitory protein (NAIP), X-linked IAP (XIAP), Human IAP1 (HIAP1), and HIAP2 suppress apoptosis through the inhibition of caspases (for review, see Martin, 2002; Salveson and Duckett, 2002; Vaux and Silke, 2003). Their activity can in turn be inhibited by three different proteins, Smac/DIABLO, Omi/HtrA2, and XIAPassociated factor 1 (XAF1) (Liston et al., 2001; Verhagen and Vaux, 2002; Srinivasula et al., 2003; Yang et al., 2003). Recent studies reveal the essential role of IAPs in the intracellular pathways for neurotrophic factors in neuronal cells (Wiese et al., 1999; Perrelet et al., 2002). Glial cell-derived neurotrophic factor (GDNF) induces an upregulation of two IAPs (XIAP and NAIP) that are essential for the neuroprotective effect of GDNF on motoneurons after axotomy (Perrelet et al., 2002).

To investigate whether IAPs and their inhibitors XAF1, Smac/ DIABLO, and Omi/HtrA2 may play a role in the resistance of mature motoneurons to axotomy, we analyzed the expression and localization of these proteins in neonatal and adult motoneurons. In this study, we demonstrate that differential regulation of endogenous IAPs and XAF1 in adult motoneurons may be responsible for their resistance to axotomy. When the ratio of XAF1 was increased with respect to XIAP, the natural resistance of the adult motoneurons to axotomy was abolished. These results suggest that the regulation of XIAP and XAF1 expression may be essential for the survival of adult motoneurons after nerve injury.

\section{Materials and Methods}

Adenoviral vector production. The preparation of the adenoviral vectors for adv-XAF1, adv-XIAP, adv-HIAP2, and adv-NAIP has been described previously (Senba et al., 1991; Liston et al., 1996, 2001).

Sciatic nerve axotomy, motoneuron labeling with fluorogold, and adenoviral vector administration. Three-, $10-$, and 14 -d-old and adult ( $<1$ year) rats (Sprague Dawley) were anesthetized with pentobarbital $(50 \mathrm{mg} / \mathrm{ml}$; Nembutal; Narconen), and the left sciatic nerve was transected. The experimental procedures were approved by the Ethical Committee for Animal Experimentation of the Geneva Veterinary Office. To specifically label the sciatic motoneuron pool, the proximal stump was capped with a small cupule containing $2.5 \mu \mathrm{l}$ of a fluorescent retrograde tracer, fluorogold (Fluorochrome, Englewood, CO) at a final concentration of 2.5\% (Perrelet et al., 2002). Recombinant adenoviral vectors [adv-XAF1, adv-LacZ, adv-XIAP, and adv-green fluorescent protein (GFP)] were added at the indicated titer into the cupule. The incision was sutured, and the rats were placed on a warming plate to recover from the anesthesia.

Motoneuron labeling by intramuscular injection of fluorogold into the gastrocnemius muscle. For the injection of fluorogold and the viral vectors into the gastrocnemius muscle, a small incision was made in the skin of the left calf muscle. A total volume of $3 \mu \mathrm{l}$ of fluorogold at $2.5 \%$ (Perrelet et al., 2002), with or without the viral vector at the indicated viral titer, was injected into the gastrocnemius muscle in three different regions (median, proximal and distal) using a Hamilton (Reno, NV) syringe. The skin was then sutured, and the rats were kept on a warming plate to recover from the narcosis.

Histological analysis and motoneuron counting. The animals were decapitated at the indicated times after axotomy with an overdose of pentobarbital (Nembutal; Narconen) and perfused transcardially with $4 \%$ paraformaldehyde in PBS. The spinal cords were removed, postfixed, cryoprotected in $20 \%$ sucrose, and sectioned at $30 \mu \mathrm{m}$ on a cryostat. To determine the number of surviving motoneurons, serial sections were viewed under a ReichertJung fluorescent microscope with a UV filter. On each section, fluorogoldlabeled sciatic motoneurons were counted in the ventral horn of the spinal cord in segments L3-L6 as described previously (Perrelet et al., 2000, 2002).
Antibodies. The immunostaining for XIAP, XAF1, HIAP2, and NAIP was assessed with specific rabbit polyclonal antibodies to the respective proteins as described previously (Xu et al., 1997a,b, 1999; Li et al., 1998a; Liston et al., 2001; Perrelet et al., 2002). The polyclonal antibodies were raised against the full proteins (expressed in Escherichia coli as fusion proteins) with the exception of NAIP, in which case a $1.0 \mathrm{~kb}$ fragment of the open reading frame corresponding to the BIR domain was used as the immunogen.

The immunostaining for XIAP was done using a rabbit polyclonal antibody (pAb) that recognizes all of the individual BIR and RING finger fragments that were expressed in vitro and characterized by $\mathrm{Li}$ et al. (1998a) and Xu et al. (1999); this same Ab was used to label motoneurons in the rat spinal cord (Perrelet et al., 2002). The XAF1 pAb was generated by immunizing rabbits with a glutathione $S$-transferase-XAF1 fusion protein (Liston et al., 2001); this Ab is primarily directed against the $\mathrm{C}$ terminus because it does not recognize an XAF1 isoform that lacks the two C-terminal zinc fingers. We have compared the immunostaining of rat motoneurons using this $\mathrm{Ab}$ and a monoclonal antibody $(\mathrm{mAb})$ prepared by P. Liston, W. G. Fong, and R. G. Korneluk (unpublished results); we found identical staining of the motoneurons in the spinal cord. The immunostaining for HIAP2 was done using a rabbit pAb prepared and characterized by Li et al. (1998a). This Ab effectively labeled motoneurons in the rat spinal cord (Perrelet et al., 2002). The immunostaining for NAIP was done using a rabbit pAb prepared and characterized by Xu et al. (1997a,b). Using the method described by Perrelet et al. (2002), this Ab labeled motoneurons in the rat spinal cord.

In Western blotting, the XIAP and XAF1 antibodies bound to proteins with relative molecular weights of $\sim 55-57 \mathrm{kDa}$ (XIAP) and $\sim 35 \mathrm{kDa}$ (XAF1; Fig. $1 A$ ), which were in good agreement with previous findings in different tissues and cell lines (Fong et al., 2000; Liston et al., 2001; Leaman et al., 2002). Smac/DIABLO was immunostained with an affinity-purified polyclonal anti-human Smac/DIABLO that also detected mouse and rat Smac/DIABLO (R \& D Systems, Minneapolis, $\mathrm{MN})$. An affinity-purified rabbit anti-human/rat/mouse Omi/HtrA2 $\mathrm{Ab}$ was used for immunostaining of the Omi/HtrA2 protein. The $\mathrm{Ab}$ detected endogenous human, rat, and mouse full-length and mitochondria-processed Omi/HtrA2 (R \& D Systems).

Western blot analysis, quantification, and statistical analysis. The animals were decapitated at the indicated times, and the entire lumbar spinal cord was removed and homogenized in an extraction buffer (PBS, pH 7.4, $1 \%$ NP-40, $0.5 \%$ sodium deoxycholate, $0.1 \%$ SDS, and $5 \mu \mathrm{M}$ DTT). The tissue was then boiled for $3 \mathrm{~min}$, sonicated, and incubated for $20 \mathrm{~min}$ at $4^{\circ} \mathrm{C}$ with the addition of PMSF $(1 \mathrm{~mm})$. Cell debris were removed by high-speed centrifugation for $20 \mathrm{~min}$ at $4^{\circ} \mathrm{C}$. An equal volume of sample containing $15 \mu \mathrm{g}$ of protein was mixed with an SDS reducing buffer, separated on a $10 \%$ SDS-polyacrylamide gel, and electroblotted onto a nylon membrane (Macherey-Negel, Düren, Germany). After $1 \mathrm{hr}$ of "blocking" at room temperature (PBS, $0.1 \%$ Tween 20 , and $5 \%$ nonfat dry milk), the membrane was incubated with the primary $\mathrm{Ab}$ (1:500 rabbit polyclonal anti-XIAP; R \& D Systems) overnight at $4^{\circ} \mathrm{C}$, followed by incubation with anti-rabbit IgG horseradish peroxidase (HRP)-linked $\mathrm{Ab}(1: 3000,1 \mathrm{hr}$ at room temperature; Amersham Biosciences, Buckinghamshire, UK), and reblotted with mouse monoclonal anti-XAF1 (1:50; Liston et al., unpublished observations) followed by incubation with anti-mouse IgG-HRP (1:3000). Staining of the protein was done by chemiluminescence (ECL; Amersham Biosciences). For each experiment, the membrane was stripped in $62.5 \mathrm{~mm}$ Tris- $\mathrm{HCl}, \mathrm{pH} 6.5,100 \mathrm{~mm}$ $2-\beta$ mercaptoethanol, and $2 \%$ SDS at $50^{\circ} \mathrm{C}$ for $30 \mathrm{~min}$, and an $\mathrm{Ab}$ to GFAP (1:250, $1 \mathrm{hr}$ at room temperature; Sigma, Stans, Switzerland) was applied; the blots were revealed by ECL with an HRP-linked goat Ab (1:3000). In other experiments, the membranes were incubated with anti-Smac/DIABLO (1:1000) or anti-Omi/HtrA2 (1:1000) followed by incubation with anti-rabbit IgG horseradish peroxidase (HRP-linked $\mathrm{Ab}, 1: 3000)$. All of these experiments were done in at least three different animals for each condition. The optical density of the different bands was measured by scanning the gels and determining the number of pixels per surface area (Scion Corp., Frederick, MD).

Immunohistochemistry, quantification, and statistical analysis. Twelve micrometer sections of the lumbar spinal cord were mounted on slides, washed three times in PBS, and blocked for 20 min with PBS containing 
BSA (1\%) and Triton X-100 (0.3\%). The anti-GFP primary Ab (rabbit polyclonal, 1:500; Molecular Probes, Eugene, OR) and the anti-XIAP, -NAIP, -HIAP2, and -XAF1 primary antibodies (rabbit polyclonals, 1:300; described by Xu et al., 1997, 1999; Li et al., 1998a; Liston et al., 2001) were diluted in the blocking solution, and sections were incubated overnight at $4^{\circ} \mathrm{C}$. After three washes with PBS, sections were incubated with a secondary anti-rabbit rhodamine-conjugated Ab (1:200; Jackson ImmuneResearch, West Grove, PA) that was applied for $45 \mathrm{~min}$ at room temperature. The sections were coverslipped using Fluorosave (Calbiochem, La Jolla, CA) and analyzed with a Zeiss (Oberkochen, Germany) microscope equipped with a digital camera (Axiocam; Zeiss). The controls were done in the absence of the primary $\mathrm{Ab}$, and in all cases, they were negative. The IAP expression level in motoneurons was measured using the NIH Image 1.6 program. All of the motoneurons $(\sim 10-15$ per section) on five sections were measured for each animal. Each group represents at least three or more animals.

Double-labeling immunofluorescence. Rabbit polyclonal anti-XIAP and mouse monoclonal anti-XAF1 (Liston et al., unpublished observations) primary antibodies were used in combination at 1:300 and 1:20, respectively; the secondary antibodies were anti-rabbit FITC-conjugated $\mathrm{Ab}$ (1:200; Jackson ImmunoResearch) and Alexa 568 goat anti-mouse IgG (1:500; Molecular Probes). Immunohistochemistry was performed as described above.

Terminal deoxynucleotidyl transferase-mediated biotinylated UTP nick end labeling. The ApoTag peroxidase in situ apoptosis detection kit (Chemicon, Temecula, CA) was used according to the manufacturer's protocol. Briefly, $12 \mu \mathrm{m}$ paraffin sections of the spinal cord from postnatal rats $(3,10$, and $14 \mathrm{~d})$ were deparaffinized in xylene and decreasing concentrations of ethanol followed by incubation in proteinase $\mathrm{K}$ ( 10 $\mu \mathrm{g} / \mathrm{ml}$ ) for $15 \mathrm{~min}$ at room temperature. After quenching of the endogenous peroxidase ( $3 \%$ hydrogen peroxidase for $5 \mathrm{~min}$ at room temperature), digoxigenin-labeled nucleotides were enzymatically added by terminal deoxynucleotidyl transferase (TdT) at the $3^{\prime}$-hydroxyl ends of double-stranded or single-stranded DNA termini by incubation with the working strength $\mathrm{TdT}$ for $1 \mathrm{hr}$ at $37^{\circ} \mathrm{C}$ in a humidified atmosphere. The anti-digoxigenin $\mathrm{Ab}$ that is conjugated to peroxidase was applied for 30 min at room temperature and then developed with $0.05 \%$ diaminobenzidine for $5 \mathrm{~min}$. Samples were counterstained with $0.1 \%$ methyl green and coverslipped with a mounting medium. Both the rodent mammary gland ( $4 \mathrm{~d}$ after weaning of rat pups) and the large intestine were used as positive controls because they undergo extensive apoptosis.

\section{Results}

Expression levels of XIAP increase during development as opposed to those of the inhibitor XAF1, which decrease over time

Our initial goal was to determine whether there was a difference in the expression level of IAPs and the three known inhibitors XAF1, Smac/DIABLO, and Omi/HtrA2 during the course of development in the spinal cord. By immunoblotting, we examined the expression of XIAP and the three inhibitors at postnatal day 3 (P3), P10, and P14 and in the adult lumbar spinal cord (Fig. 1A). There was, in general, no overall variation in the level of Smac/ DIABLO and Omi/HtrA2 during development, except for Omi/ HtrA2, in which there was an unexplained decrease at P14 (Fig. $1 A)$. In contrast, XAF1 expression decreased between neonatal day 3 (P3) and the adult, whereas the endogenous level of XIAP increased over the same period (Fig. $1 A$ ). Quantification of the immunoblots showed that the level of XIAP increased up to P14 and then stabilized (Fig. 1A,B). In contrast, there was a steady decrease in the level of XAF1 during development, and in the adult, there was $\sim 10 \%$ of the initial level found at P3 (Fig. $1 A, C$ ).

Using immunohistochemical analysis, we studied the localization of XIAP on sections of neonatal and mature rat spinal cord (P14). At both ages, XIAP expression was observed in motoneurons and less intensely in other cells in the gray matter of the spinal cord (Figs. $2 A, B, 3 B, E$ ). By measuring quantitatively the
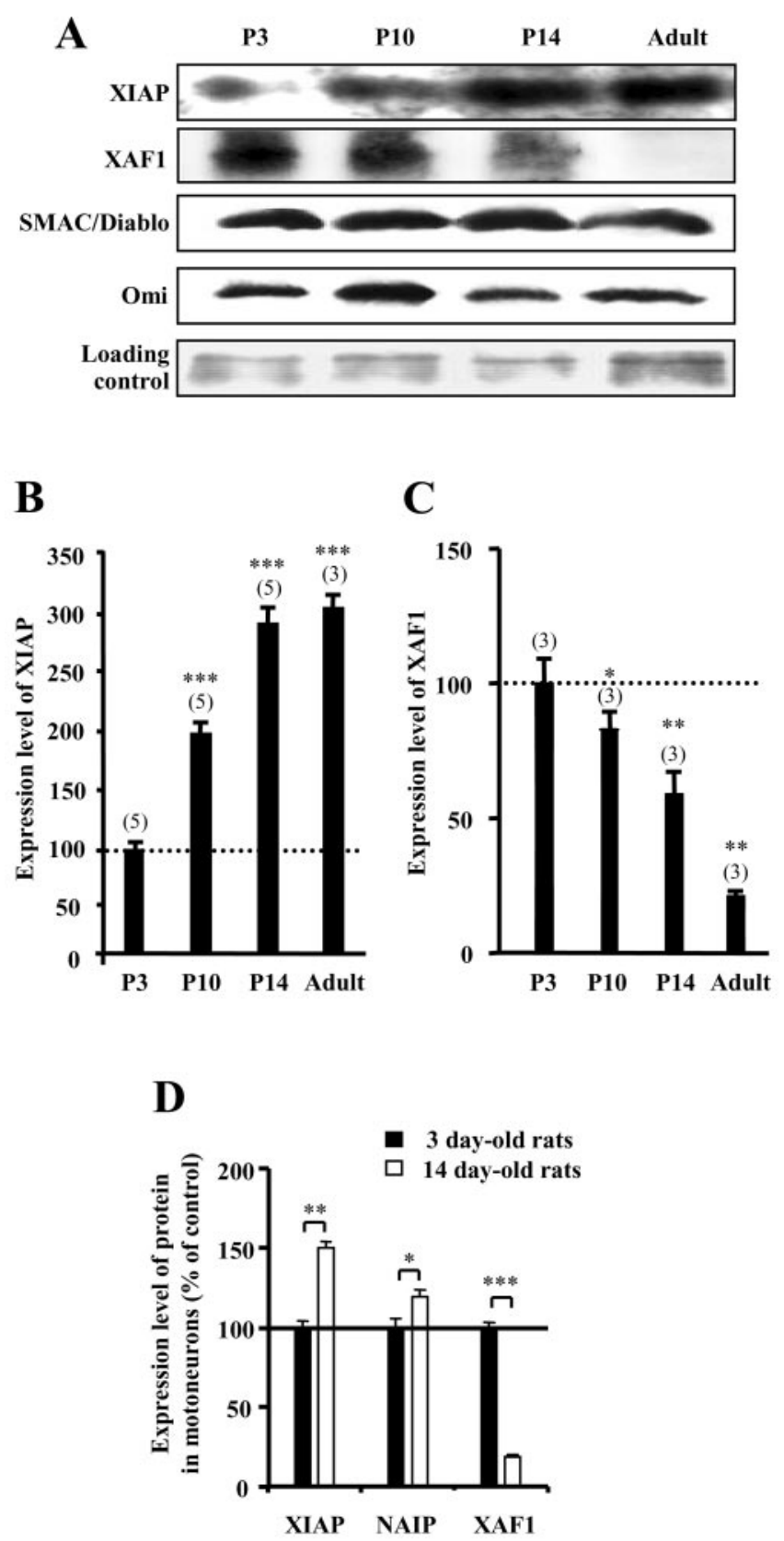

Figure 1. Expression levels of XIAP, Smac/DIABLO, Omi/HtrA2, and XAF1 during postnatal development in the spinal cord. $A$, Immunoblot analysis of endogenous expression of XIAP, $\mathrm{Smac} / \mathrm{DIABL} 0,0 \mathrm{mi} / \mathrm{HtrA2}$, and XAF1. The gels are representative results of three or more different animals for each condition. $B, C$, Quantification of the immunoblot analysis of endogenous expression of XIAP and XAF1, respectively, in the lumbar spinal cord of P3, P10, P14, and adult rats. Values in brackets indicate the number of animals. The immunoblots were quantified by densitometry analysis of the bands \pm SEM. GFAP was used as a loading control; $100 \%$ corresponds to the value at P3. D, Comparison of the expression level of IAPs and XAF1 in individual motoneurons from the 3- and 14-d-old rats in Figure 2. Values were normalized to the level in 3-d-old rats (100\%). No quantification of HIAP2 staining was performed because of the absence of this protein in 3-d-old motoneurons; $100 \%$ corresponds to the value at P3 (Dunnet's multiple-comparison test: ${ }^{*} p<0.05 ;{ }^{* *} p<0.01$; ${ }^{* * *} p<0.0005$ ).

intensity of the fluorescent labeling specifically in the motoneurons, it was possible to show that the expression of XIAP had increased by $50 \%$ between postnatal days 3 and 14 (Fig. $1 D$ ). Moreover, the level of XIAP expression in adult motoneurons $(<1$ year $)$ was comparable with that observed in 14-d-old animals (data not shown). 

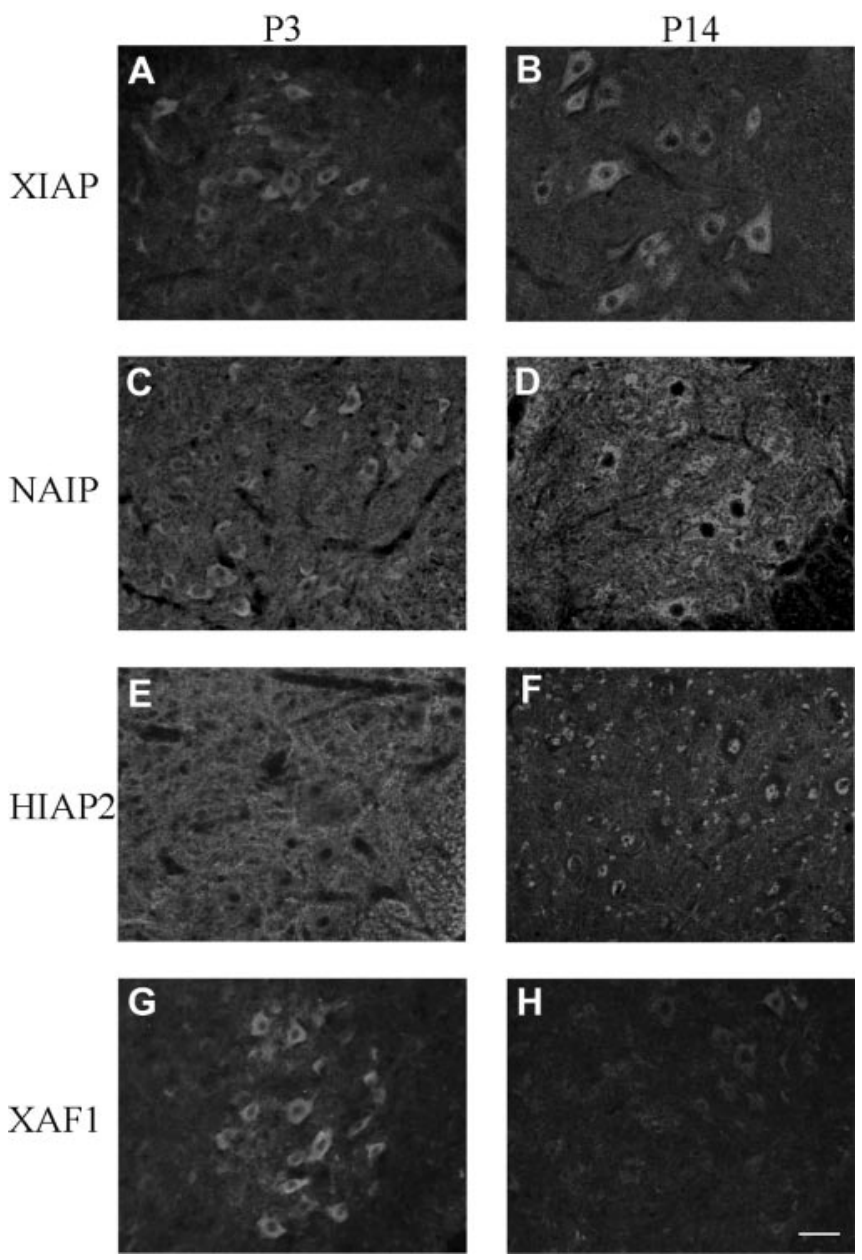

Figure 2. Immunostaining of XIAP, NAIP, HIAP2, and XAF1 in lumbar spinal cord sections from 3- and 14-d-old rats. $A, C, E, G$, Photographs of the lumbar ventral horn of the spinal cord from 3-d-old rats at low magnification. $B, D, F, H$, Photographs of the lumbar ventral horn of the spinal cord from 14-d-old rats at low magnification. The results are representative of four or more different animals for each condition. Antibodies used: $A, B$, anti-XIAP; $C, D$, anti-NAIP; $E, F$, anti-HIAP2; $G, H$, anti-XAF1. Scale bar, $200 \mu \mathrm{m}$.

An obvious extension of these immunohistochemical studies was to examine the expression level of two other IAP proteins (NAIP and HIAP2) and the inhibitor XAF1 specifically in the spinal cord motoneurons. NAIP was expressed in motoneurons, and its level was significantly increased between postnatal days 3 and 14 (Fig. 2C,D; for quantification, see Fig. 1D). However, HIAP2 was not expressed in developing motoneurons (P3; Fig. $2 E$ ) but was expressed in mature motoneurons (P14) as well as in other cells of the spinal cord (Fig. $2 F$ ). Whereas XIAP and NAIP were expressed in the cytoplasm in motoneurons, HIAP2 was expressed in the nucleus only at later ages (P14; Fig. 2F).

Because there was no alteration in the levels of Smac/DIABLO and Omi/HtrA2 during spinal cord development, we concentrated on examining the expression of XAF1 in the motoneurons. Immunohistochemical studies showed that XAF1 is expressed mainly in motoneurons in neonatal animals (P3; Figs. 2G, 3A) and is nearly undetectable at later developmental stages (P14 and adult; Figs. $2 \mathrm{H}, 3 \mathrm{D}$; for quantification, see Fig. $1 \mathrm{D})$. Furthermore, using double-label immunohistochemical staining, it was possible to show that XAF1 and XIAP were localized in the same motoneurons at both P3 and P14 (Fig. 3).
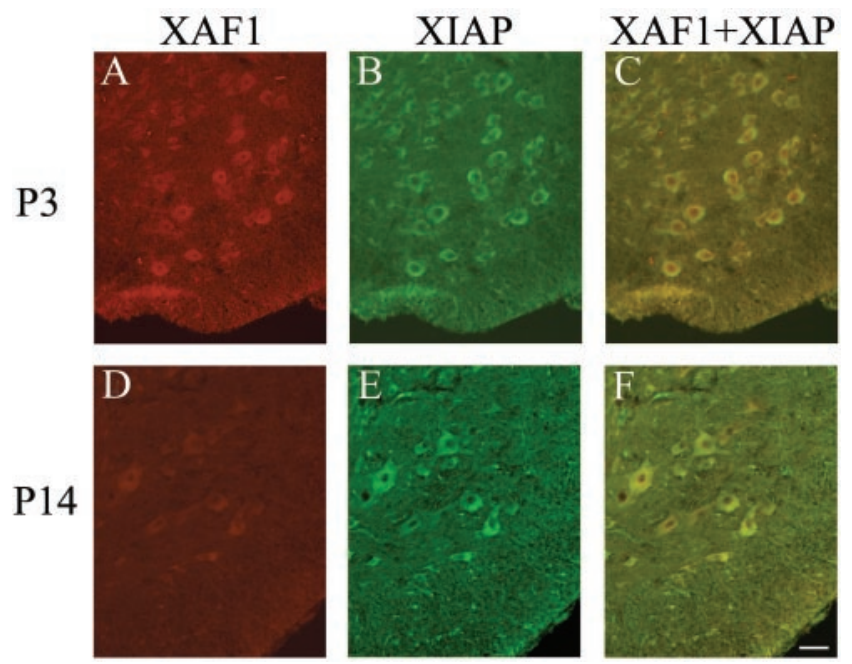

Figure 3. Immunostaining of XIAP polyclonal and XAF1 monoclonal antibodies in lumbar spinal cord sections from 3- and 14-d-old rats. Photographs of the lumbar spinal cord from 3-d-old ( $A-C$ ) and 14-d-old ( $D-F)$ rats show the labeled motoneurons with an mAb to XAF1 ( $A$, $D)$, a pAb to XIAP $(B, E)$, and merged images of XAF1 and XIAP $(C, F)$. Note that XAF1 and XIAP are located in the same motoneurons. Also note that the secondary Ab for the polyclonal XIAP Ab appears in green because of the FITC conjugate. Scale bar, $200 \mu \mathrm{m}$.

\section{Level of expression of XIAP and XAF1 in the spinal cord} correlates with the age-related resistance of motoneurons to axotomy-induced cell death

Motoneuron cell death resulting from an apoptotic mechanism at P3 was confirmed by terminal deoxynucleotidyl transferasemediated biotinylated UTP nick end-labeling (TUNEL) staining to detect DNA fragmentation. We detected TUNEL-positive motoneurons in 3-d-old rats at 1 week after axotomy of the sciatic nerve (Fig. $4 B$ ) as opposed to controls in which no labeling occurs (Fig. $4 A$ ). In contrast, no TUNEL-positive stained motoneurons were found in a P14 axotomized rat (data not shown). As suggested in the ApoTag manual, we used methyl green counterstaining to visualize the morphological characteristics of the motoneurons after axotomy (Fig. 4C,D). Motoneurons appeared similar to those described by Li et al. (1998b) after sciatic nerve axotomy in the mouse. Indeed, many motoneurons had degenerated, and others were atrophic (Fig. $4 B$, arrows); there was visible cell shrinkage and a hyperchromatic cytoplasm that are both characteristic features of apoptosis.

To determine whether the antiapoptosis protein XIAP could be involved in the resistance of mature motoneurons to injury, we first correlated the degree of survival of sciatic motoneurons after axotomy with the level of XIAP and XAF1 expression determined by immunoblotting. The motoneurons in the sciatic pool were quantified by applying a fluorescent retrograde tracer (fluorogold) onto the end of the transected sciatic nerve at different ages of development (Vejsada et al., 1995). The fluorescent tracer was retrogradely transported by the lesioned nerves into the motoneuron cell bodies of the spinal cord. In the adult rat, the sciatic motor pool contains $\sim 1900$ motoneurons (Vejsada et al., 1995; Perrelet et al., 2000).

Whereas 1900 motoneurons were observed in mature (P14) and adult ( $>1$ year) animals, only $50 \%$ of these cells survived at 1 week after axotomy in neonatal animals (P3; Fig. 5A). At 3 weeks after axotomy, the number of surviving motoneurons continued to decrease in young animals (P3, 400 cells), whereas in P14 and adult rats, no degeneration was observed (data not shown). Therefore, the increased resistance of motoneurons to axotomy 

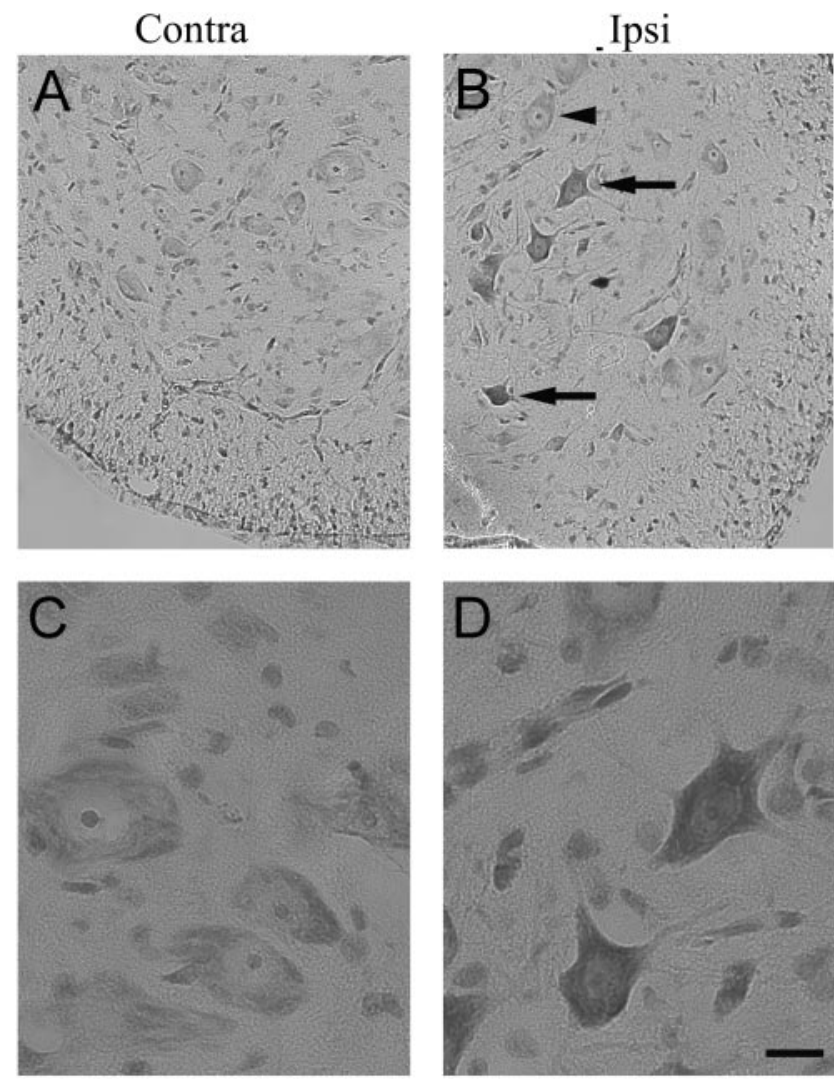

Figure 4. Labeling of the lumbar spinal cord using TUNEL and methyl green from 3-d-old postnatal rats at 1 week after unilateral transection of the left sciatic nerve. Many normal motoneurons are seen in the contralateral (Contra; control) side of the anterior horn of the spinal cord ( $A$ ). In contrast, on the ipsilateral (Ipsi) side (transected side), few motoneurons appear normal (arrowhead) as opposed to many motoneurons that appear to be undergoing an apoptotic process ( $B$, arrows). At a higher magnification, no TUNEL-positive nuclei are seen in the contralateral side (C). Typical apoptotic-appearing nuclei can be seen in the ipsilateral side (D). Scale bar: $A, B, 200 \mu \mathrm{m} ; C, D, 65 \mu \mathrm{m}$.

(Fig. $5 A$ ) correlated with the increased expression of XIAP (Fig. $1 A, B)$ and the decreased expression of XAF1 (Fig. $1 A, C$ ) with increasing age of the animals.

Differential expression of IAPs and their inhibitor XAF1 after axotomy could be responsible for the resistance of adult motoneurons to cell death. We therefore compared the level of these proteins in control and axotomized animals after 1 week survival in neonatal (P3) and mature (P14) rats. An analysis of XIAP levels by Western blotting did not reveal any difference between controls and injured animals either in neonates or in mature rats (data not shown). This method is probably not sensitive enough to detect a small change in XIAP level in the sciatic motoneuron pool because the entire lumbar spinal cord was analyzed and not exclusively the motoneurons that represent only a small fraction of the total cells (Perrelet et al., 2002). Therefore, we undertook a quantitative immunohistochemical analysis of IAP in individual motoneurons to increase the sensitivity of the determination.

In neonatal rats, the sciatic nerve lesion resulted in a highly significant decrease in the immunohistochemical staining of XIAP, NAIP, and XAF1 in the injured motoneurons as compared with the contralateral side or with unoperated animals (Fig. $6 A, B, D, E, J, K$; for quantification, see Fig. $5 B$ ). Retrograde labeling with fluorogold provided a means for localizing the surviving axotomized motoneurons in the sciatic motor pool (Vejsada et al., 1995; data not shown). In this way, it was possible to show that there was a co-localization of fluorogold along with XIAP, NAIP, and XAF1 in some of the surviving motoneurons (Fig. $6 B, C, E, F, K, L)$. However, other motoneurons outside the sciatic pool also expressed the IAPs and the inhibitor XAF1 (Figs. $6 B$, Fig. $7 B$, arrows). In contrast to XIAP and NAIP, HIAP2 was absent in both ipsilateral and contralateral motoneurons (Figs. $2 E$, $6 G-I)$.

As opposed to neonatal animals, the peripheral nerve lesion in older rats (P14) did not induce a decrease in XIAP expression in injured motoneurons compared with the contralateral side or with unoperated animals (Fig. $7 A-C$; for quantification, see Fig. $5 C)$. HIAP2 expression, which is present only in the nucleus, was unaffected by the nerve lesion (Fig. 7G-I; for quantification, see Fig. $5 C$ ). In contrast to XIAP and HIAP2, the expression of NAIP was decreased by $25 \%$ in adult injured motoneurons (Fig. $5 C$ ). However this decrease was not as important as that observed in the neonatal animals after axotomy (60\%; Fig. 7D-F; for quantification, see Fig. 5B). Finally, XAF1 expression, which was already low in mature animals (Fig. $1 D$ ), was significantly reduced in the ipsilateral motoneurons compared with their contralateral counterparts (Fig. 7J-L; for quantification, see Fig. $5 C$ ).

\section{XAF1 administration decreases survival of injured mature motoneurons}

In previous studies, we demonstrated that XIAP, NAIP, HIAP1, and HIAP2 could prevent motoneuron degeneration after sciatic nerve axotomy in 3-d-old rats (Perrelet et al., 2000, 2002). In addition, we showed that co-infection with adv-XAF1 inhibited the survival-promoting effects of both XIAP and NAIP (Perrelet et al., 2002). The goal of the present studies was to determine whether there was a correlation between the endogenous levels of IAP in mature motoneurons and their increased resistance to axotomy. Therefore we inhibited the effects of IAP in mature motoneurons (P14) and determined whether these cells were still capable of surviving.

To address this question, we used two different methods of labeling the motoneurons in the spinal cord after axotomy. In one case, we applied the retrograde tracer fluorogold onto the cut end of the sciatic nerve; this tracer labels all of the motoneurons in the sciatic pool in the spinal cord ( $~ 1900$ cells; Fig. 8 A, filled bars). However, when we infect this same motoneuron pool with an adenoviral vector that contains a reporter gene such as lac Z, then only $14 \%$ of the motoneurons express lac Z (i.e., 300 motoneurons; Perrelet et al., 2000). These results suggest that only a subpopulation of motoneurons can be infected by the adenoviral vector; similar results have been reported by other workers (Baumgartner and Shine, 1997, 1998; Gimenez y Ribotta et al., 1997; Gravel et al., 1997).

Under these conditions, in which all 1900 motoneurons are labeled by fluorogold, we would predict that only 300 of these cells would be affected by the administration of adv-XAF1 and would die. Indeed, after sciatic nerve axotomy in the mature rat (P14), the application of adv-XAF1 caused a loss of $\sim 300$ motoneurons (Fig. 8A). Similar results were observed when advXAF1 was applied in adult animals ( $<1$ year old) using the same technique (data not shown). In control experiments using advlac $\mathrm{Z}$ alone, there was no loss of motoneurons.

In the Bcl-2 family, it has been shown that it is the ratio of proapoptotic and antiapoptotic molecules that is responsible for the sensitivity to cell death. For this reason, we investigated whether an alteration in the ratio of XIAP and XAF1 in the motoneurons would affect the ability of the mature motoneurons to degenerate. We co-applied adv-XIAP and adv-XAF1 at the same 
viral titer, but this particular combination did not prevent the loss in motoneurons observed with adv-XAF1 application alone (Fig. 8A). However, when the adv-XIAP titer was 10 -fold higher than the adv-XAF1 titer used in the previous experiment, there was no loss of motoneurons compared with a single application of the same quantity of adv-XAF1 or adv-LacZ (Fig. $8 A$ ). We observed comparable effects with combinations of adv-NAIP and adv-XAF1 and with adv-HIAP2 and adv-XAF1 (data not shown). Therefore, by artificially altering the ratio of IAP and its inhibitor, it was possible to differentially affect the survival of the adult motoneurons.

To determine whether XAF1 was by itself a proapoptotic stimulus, we co-injected the viral vector along with fluorogold directly into the gastrocnemius muscle and allowed the vector and the tracer to be retrogradely transported to the motoneuron cell bodies in the spinal cord. We had previously shown that this technique permits the infection of $\sim 200$ sciatic motoneurons (as opposed to 300 when applied onto the nerve stump) without performing a nerve lesion (Perrelet et al., 2000). Under these conditions of administration, no loss of motoneurons was observed (Fig. $8 \mathrm{~B}$ ), suggesting that XAF1 was not acting as an apoptotic enhancer.

The second means of labeling the motoneurons to study the effects of adv-XAF1 application involves prelabeling the motoneurons in the sciatic pool by means of an adenoviral vector expressing the reporter gene GFP. Under these conditions, only those motoneurons transfected with the adenoviral vector are labeled (Fig. 9). Likewise, in animals in which adv-GFP was co-applied with adv-lac Z onto the nerve stump at the time of axotomy, all of the adenoviralinfected motoneurons ( $\sim 300$ cells) exhibited GFP-positive staining at 1 week after axotomy (Fig. $9 A$ ).

In this way, we could visualize the selective loss of adenoviralinfected motoneurons after administration of adv-XAF1 in adult axotomized animals. As seen in Figure 9B, no GFP-positive motoneurons were observed in animals treated with adv-XAF1, along with adv-GFP, using a cupule applied to the end of the cut nerve at the time of axotomy. However, when adv-GFP plus advXAF1 were injected into the gastrocnemius muscle, all of the adenoviral-infected motoneurons ( $\sim 200$ cells in the case of muscle injection) exhibited GFP-positive staining using an Ab to GFP (Fig. 9C). These results suggest that all of the adenoviral-infected motoneurons degenerated because of the expression of XAF1 after the sciatic nerve lesion but not in the absence of an injury to the nerve (i.e., muscle injection).

\section{Discussion}

\section{Apoptotic signals and their inhibitors for controlling} neuronal cell death

It is generally accepted that there is a complex balance between cell death and survival-inducing signals that can determine the destiny of neurons. Pathogenesis of many human diseases is associated with the deregulation in the equilibrium between cell death and survival. Thus, disruption in this balance can have important consequences in both the immature and adult nervous systems.

Two classes of cellular apoptotic inhibitors have been identi-
B

- P3 + 7 days Contralateral

ㅁ $\mathbf{P} 3+7$ days Ipsilateral

C

- P14 + 7 days Contralateral

口 $\mathbf{P 1 4}+7$ days Ipsilateral
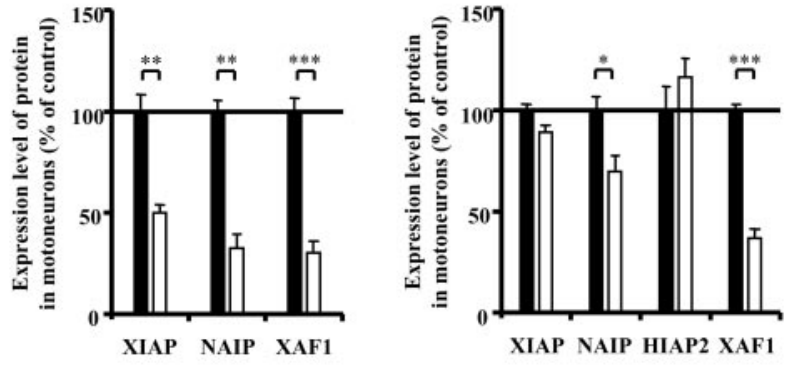

Figure 5. Effect of sciatic nerve axotomy on motoneuron degeneration and quantification of IAP and XAF1 expression in individual motoneurons from immunostained sections of Figures 6 and 7. A, Quantification of fluorogold-labeled motoneurons at 1 week survival after axotomy in 3-d-old (P3), 10-d-old (P10), 14-d-old (P14), and adult (>1 year) rats. The numbers of surviving 3-d-old rats (P3); immunostaining is shown in Figure 4. Values were normalized to the protein level in the contralateral side, which corresponds to unoperated animals of the same age (21-d-old rats). The results are representative of 4 or more different animals for each condition (Dunnet's multiple comparison test: ${ }^{*} p<0.05 ;{ }^{* *} p<0.005 ;{ }^{* *} p<0.0005$ ).

\section{P3 +7 days post-axotomy}
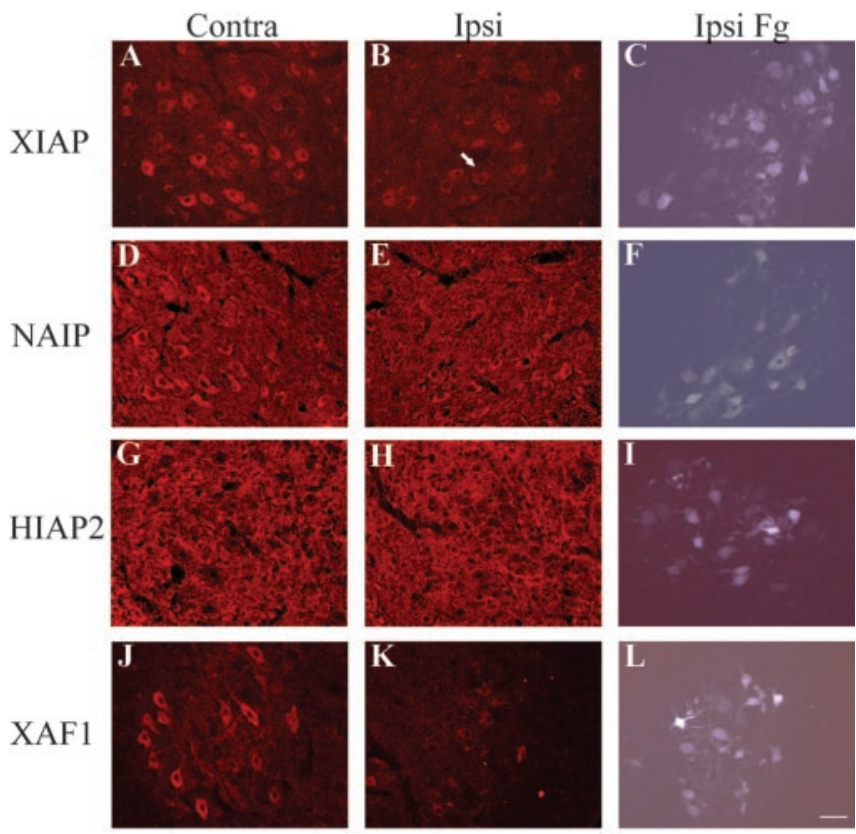

Figure 6. Immunostaining of IAP and XAF1 in lumbar spinal cord sections $7 \mathrm{~d}$ after sciatic nerve transection in 3-d-old rats. $A, D, G, J$, Contralateral (Contra) region of the ventral spinal cord in 3-d-old rats ( $+7 \mathrm{~d}$ survival) showing uninjured motoneurons. The pattern of immunostaining on the contralateral side was the same as in lumbar spinal cord in unoperated animals of the same age (10-d-old rats). B, E, H, K, Ipsilateral (Ipsi) region of the ventral spinal cord in 3-d-old rats ( $+7 \mathrm{~d}$ after axotomy) showing injured motoneurons. C, F, I, L, Fluorogold (Fg) labeling of injured motoneurons present in $B, E, H$, and $K$. Antibodies used: $A-C, X I A P ; D-F$, NAIP; $G-I, H I A P 2 ; J-L$, XAF. The results are representative of four or more different animals for each condition. $\mathrm{P} 3$ refers to 3 -d-old rats. The arrow in $B$ shows a motoneuron that expresses XIAP and does not belong to the sciatic motor pool. Scale bar, $200 \mu \mathrm{m}$. 
P14 + 7 days post-axotomy
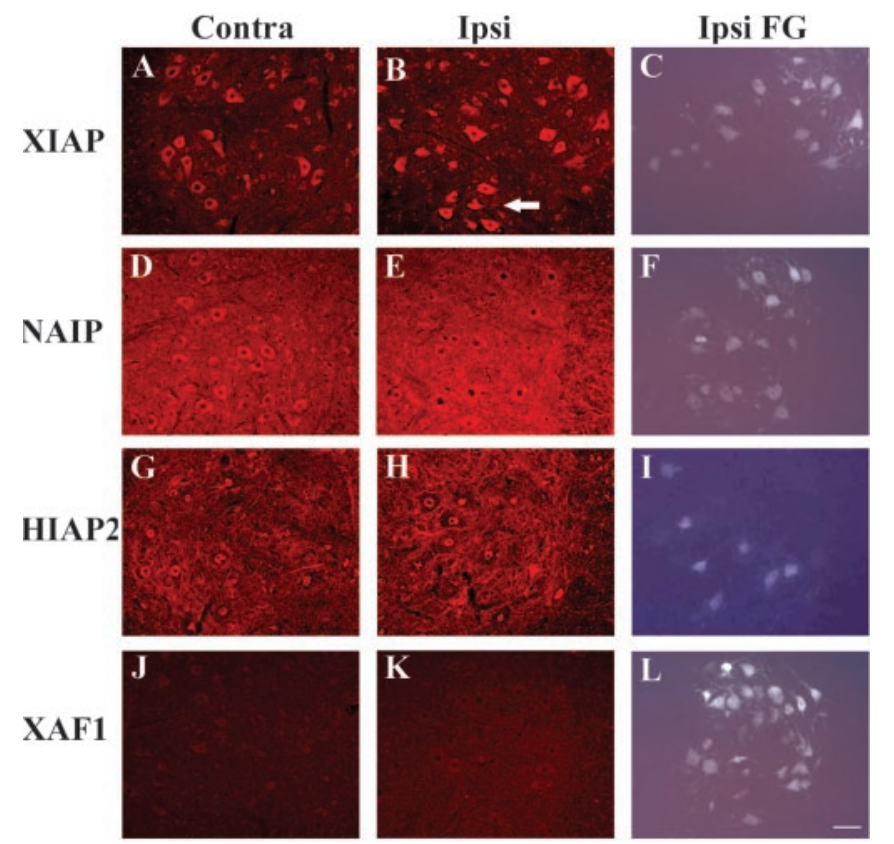

Figure 7. Immunostaining of IAP and XAF1 in lumbar spinal cord sections $7 \mathrm{~d}$ after sciatic nerve transection in 14-d-old rats. $A, D, G, J$, Contralateral (Contra) region of the ventral spinal cord in 14-d-old rats ( $+7 \mathrm{~d}$ survival) showing uninjured motoneurons. The pattern of immunostaining on the contralateral side was the same as in lumbar spinal cord in unoperated animals of the same age (21-d-old rats). $B, E, H, K$, Ipsilateral (Ipsi) region of the ventral spinal cord in 14-d-old rats ( $+7 \mathrm{~d}$ after axotomy) showing injured motoneurons. C, F, I, L, Fluorogold (Fg) labeling of injured motoneurons present in $B, E, H$, and $K$. Antibodies used: $A-C, X I A P ; D-F$, NAIP; $G-I$, HIAP2; $J-L$, XAF. The results are representative of four or more different animals for each condition. P14 refers to 14-d-old rats. The arrow in $B$ shows a motoneuron pool that expresses XIAP and does not belong to the sciatic nerve pool. Scale bar, $200 \mu \mathrm{m}$.

fied; these include members of the Bcl-2 and IAP families. Bcl-2 family members can block the mitochondrial branch of apoptosis by preventing the release of cytochrome $c$, whereas members of the IAP family can inhibit both mitochondrial and death receptor-mediating pathways of apoptosis by directly binding to and inhibiting both initiator and effector caspases (Salveson and Duckett, 2002). In the bcl-2 family, the antiapoptotic activity can be counterbalanced by the action of the proapoptotic family members such as Bax and Bid (for review, see Cory and Adams, 2002). Furthermore, it appears that the ratio of the preapoptotic and antiapoptotic family members can alter the susceptibility of cells to various apoptotic stimuli by means of the proteosome and the ubiquitination systems (Yang and Yu, 2003).

The antiapoptotic activity of IAPs is regulated by three cellular proteins identified so far in mammals, Smac/DIABLO (Verhagen and Vaux, 2002), XAF1 (Liston et al., 2001), and Omi/HtrA2 (Srinivasula et al., 2003; Yang et al., 2003); these proteins appear to interact directly with the IAP molecules to modulate their antiapoptotic activity. XAF1 is a mammalian XIAP-binding protein that was identified by a yeast two-hybrid screen (Liston et al., 2001), and in our experiments, XAF1 can inhibit the effects not only of XIAP but also of NAIP (Perrelet et al., 2002). XAF1, Smac/DIABLO, and Omi/HtrA2 are similar in that all three inhibitors are considered negative regulators of IAPs (for review, see Salveson and Duckett, 2002). Both Smac/DIABLO and $\mathrm{Omi} / \mathrm{HtrA} 2$ are released from the mitochondria, and Omi/HtrA2 appears to have a second mechanism that is related to its function as a serine protease (Srinivasula et al., 2003; Yang et al., 2003).

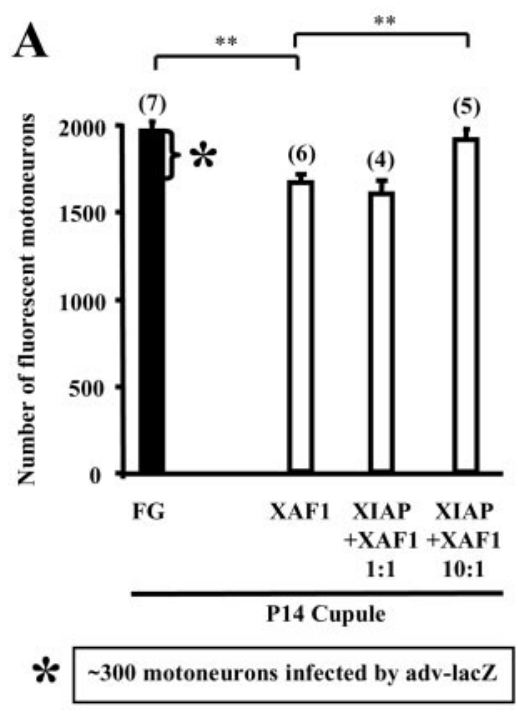

B

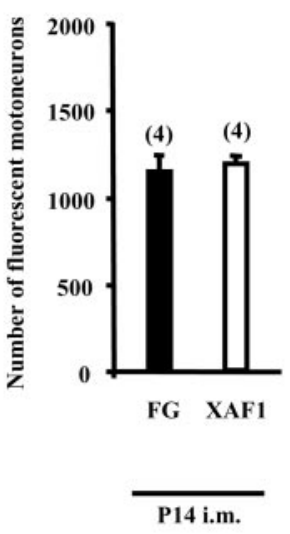

Figure 8. Motoneuron survival in 14-d-old rats after inhibition of IAP by XAF1 overexpression. $A$, The vectors and tracer [fluorogold ( $\mathrm{FG})$ ] were co-administered by direct application onto the transected sciatic nerve stump in 14-d-old rats (P14). The surviving motoneurons were counted 1 week after -axotomy. The results observed in fluorogold-treated animals (i.e., 1900 motoneurons) were the same as those obtained with adv-lacZ plus fluorogold and adv-XIAP plus fluorogold. The adv-XAF1 titer was $10^{9} \mathrm{pfu}$, whereas adv-XIAP was at $10^{9} \mathrm{pfu}$ for the experiments at 1:1 and at $10^{10}$ pfu for the experiments at 10:1. The results of adv-XAF1 alone were the same as with a co-application of adv-XAF1 $\left(10^{9} \mathrm{pfu}\right)$ plus adv-LacZ $\left(10^{10} \mathrm{pfu}\right)$. In the experiments with adv-XAF1, there was a loss of $\sim 300$ fluorogold-labeled motoneurons. $B$, Effect of XAF1 $\left(10^{9} \mathrm{pfu}\right)$ on motoneuron survival in uninjured motoneurons. The vectors and the tracer were co-administered by injection into the gastrocnemius muscle. The surviving motoneurons were counted at 1 week after injection. The results observed in fluorogold-treated animals were the same as those obtained with adv-lacZ plus fluorogold. Values in brackets indicate the number of animals. P14 i.m., Injection of the adenoviral vectors into the gastrocnemius muscle of 14-d-old-rats; P14 Cupule, application of the viral vectors onto the transected sciatic nerve of 14-d-old rats (Dunnet's multiple comparison test: ${ }^{* *} p<0.005$ ).
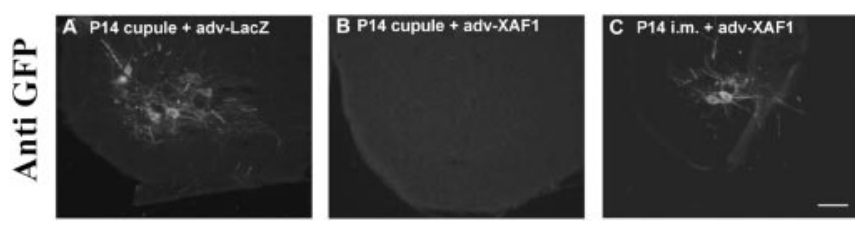

Figure 9. Effect of adv-XAF1 on adenoviral-infected motoneurons expressing GFP in 14-dold rats. $A-C$, The adenoviral-infected motoneurons were visualized by immunohistochemical analysis after infection with adv-GFP ( $\left.10^{9} \mathrm{pfu}\right)$ into the gastrocnemius muscle. After 1 week of survival, the entire lumbar spinal cord was serially sectioned and stained with an Ab to GFP (red). $A$, Infected motoneurons of 14-d-old rats after application of adv-GFP plus adv-LacZ onto the sciatic nerve stump. $B$, Infected motoneurons of 14-d-old rats after application of adv-GFP plus adv-XAF1 onto the sciatic nerve stump. C, Infected motoneurons after injection of adv-GFP plus adv-XAF1 $\left(10^{9}\right)$ into the gastrocnemius muscle of 14-d-old rats. Scale bar, $100 \mu \mathrm{m}$.

The ratio between IAPs and their inhibitor XAF1 has been demonstrated to be important in the development of cancer. For example, in most cancer cell lines, XAF1 is not expressed or is present at a very low level compared with control tissues, whereas XIAP is expressed at a high level (Fong et al., 2000; Liston et al., 2001). For this reason, it has been hypothesized that it is the elevated ratio of XIAP to XAF1 that contributes to tumorigenesis by suppressing apoptotic cell death.

In the present study, we investigated the role of IAPs and their inhibitor XAF1 on the differential resistance of neonatal and adult motoneurons to axotomy; adult motoneurons can survive after a lesion of a peripheral nerve, but neonatal motoneurons 
rapidly degenerate. Quantitative immunohistochemical analysis and immunoblotting of these proteins in motoneurons and spinal cord revealed an increase in IAP expression during postnatal development as opposed to XAF1, which decreased during the same period. Therefore, the ratio between the endogenous levels of IAPs and XAF1 is in strict opposition at the two developmental stages. Whereas XAF1 showed this negative correlation with IAP family members, the other two inhibitors, Smac/DIABLO and Omi/HtrA2, were unaltered during the course of development. These results suggest that XAF1 may play a more important role in cell death in the nervous system.

\section{The ratio between IAPs and XAF1 may contribute to the resistance or demise of motoneurons after axotomy}

Not only are the endogenous protein levels of IAP and XAF1 different in neonatal and adult motoneurons, but the regulation of these proteins after axotomy also varies. In neonatal animals, the sciatic nerve lesion induces an important decrease of IAP in injured motoneurons. Surprisingly, XAF1, which is highly expressed in these cells before the lesion, is also downregulated. The small amount of remaining IAP in injured motoneurons appears to be insufficient for preventing motoneuron cell death. However, when exogenous IAPs such as XIAP, NAIP, HIAP1, and HIAP2 are overexpressed in neonatal motoneurons (P3) by means of adenoviral vectors, axotomy-induced cell death can be prevented (Perrelet et al., 2000, 2002).

In adult animals as opposed to neonates, the level of IAPs was moderately decreased after axotomy, whereas the small amount of XAF1 almost completely disappears. These experiments suggest that the remaining IAP protein may be sufficient to prevent the activation of apoptosis. When the ratio between IAP and $\mathrm{XAF} 1$ is deregulated by overexpressing exogenous XAF1, it is possible to induce a total abrogation of the natural resistance of the mature motoneurons to axotomy. The degeneration induced by exogenous XAF1 can be overcome by expressing high levels of exogenous IAPs simultaneously with XAF1. Therefore, these experiments suggest that it may be the ratio between $\mathrm{XAF} 1$ and IAPs that confers the resistance of adult motoneurons to axotomy.

\section{Decrease in the levels of IAP and XAF1 level after axotomy}

The decrease in the immunostaining of IAP and XAF1 in neonates and adult motoneurons after axotomy indicates that the injury induces a modification in the steady-state level of these proteins. Such a modification could result from a decrease in protein synthesis, from protein degradation, or from both.

IAPs have been shown to cause their autodegradation and also the degradation of targeted proteins attributable to the presence of a RING domain in the structure (Yang and Li, 2000; Yang et al., 2000), but the regulation of this phenomenon has not been elucidated. In Drosophila, it has been recently shown that inhibitors of IAP can promote cell death by stimulating IAP self-ubiquitination and its subsequent degradation (for review, see Palaga and Osborne, 2002). Therefore, the experiments presented in this report demonstrate that IAPs and their inhibitor may also be important regulators of cell death in mammalian systems.

The mechanism of IAP inhibition by XAF1 has not been elucidated. Using in vitro techniques, Liston et al. (2001) have shown that $\mathrm{XAF} 1$ is present in the nucleus, and it can initiate a redistribution of XIAP from the cytosol to the nucleus. In contrast, our studies show that XAF1 is expressed in the cytoplasm in vivo in both neonatal and adult tissues; the localization was completely independent of the presence or absence of an apoptotic signal. In a study by Leaman et al. (2002), they observed XAF1 to be located both in the cytoplasm and in the nucleus, but they did not detect a redistribution of XIAP in cells overexpressing XAF1 in response to interferon $\beta$. Therefore, there appears to be another mechanism of IAP inhibition by XAF1 other than sequestration of XIAP into the nucleus.

Our experiments suggest that XAF1 is not in itself a proapoptotic protein because its expression in adult motoneurons in the absence of nerve injury did not induce cell death. However, under conditions of injury such as those induced by axotomy, XAF1 can enhance motoneuron susceptibility to degeneration probably by preventing the antiapoptotic activity of IAP family members. This same phenomenon has been reported in other cell types in which it has been shown that the overexpression of either XAF1 or Smac/DIABLO does not induce apoptosis but can sensitize cultured cells to apoptotic stimuli (Du et al., 2000; Verhagen et al., 2000; Liston et al., 2001).

\section{Possible mechanisms of cell death in neonatal and adult motoneurons attributable to axonal injury}

Whereas the identification of genes involved in neonatal motoneuron death after injury has been well described, those genes implicated in the survival of adult cells have received less attention. Overexpression of Akt, an essential component in the neurotrophin survival pathway, can prevent motoneuron cell death in the neonate after axotomy (Namikawa et al., 2000). Apparently, Akt does not play an essential role in adult motoneuron survival because the dominant negative form of Akt did not induce motoneuron cell death after axotomy (Namikawa et al., 2000).

Several studies have reported differential regulation of the proapoptotic protein Bax and the antiapoptotic proteins bcl-2 and bcl-xl in neonatal and adult motoneurons after axotomy (Gillardon et al., 1996; Baba et al., 1999; Schweizer et al., 2002). Because deletion of the bcl-2 gene in mice did not modify the sensitivity of adult motoneurons to axotomy (Michaelidis et al., 1996), we can assume that this protein does not play an essential role in the resistance of adult motoneurons to injury.

In conclusion, our results suggest that it may be the balance between the antiapoptotic protein XIAP and the inhibitor XAF1 that play a major role in adult motoneuron protection and neonatal sensitivity to axonal injury. This is the first demonstration that such a ratio could play an essential role in the neuron cell death process, as has been proposed for the development of carcinogenesis (Liston et al., 2001). We have only investigated one aspect of the cellular apoptotic machinery, and it is possible that various other apoptotic pathways may be affected, including death ligand receptors, death ligands themselves, FAS-associated death-domain-like interleukin$1 \beta$-converting enzyme-inhibitory protein and apoptotic proteaseactivating factor 1 . Furthermore, it will be interesting to determine whether the cell death associated with neurodegenerative diseases such as amyotrophic lateral sclerosis, Parkinson's disease, and Alzheimer's disease could result from an imbalance in the levels of IAPs and XAF1.

\section{References}

Baba N, Koji T, Itoh M, Mizuno A (1999) Reciprocal changes in the expression of Bcl-2 and Bax in hypoglossal nucleus after axotomy in adult rats: possible involvement in the induction of neuronal cell death. Brain Res 827:122-129.

Baumgartner BJ, Shine HD (1997) Targeted transduction of CNS neurons with adenoviral vectors carrying neurotrophic factor genes confers neuroprotection that exceeds the transduced population. J Neurosci 17:6504-6511.

Baumgartner BJ, Shine HD (1998) Neuroprotection of spinal motoneurons 
following targeted transduction with an adenoviral vector carrying the gene for glial cell line-derived neurotrophic factor. Exp Neurol 153:102-112.

Cory S, Adams JM (2002) The Bcl2 family: regulators of the cellular life-ordeath switch. Nat Rev Cancer 2:647-656.

de Bilbao F, Dubois-Dauphin M (1996) Time course of axotomy-induced apoptotic cell death in facial motoneurons of neonatal wild type and bcl-2 transgenic mice. Neuroscience 71:1111-1119.

de Bilbao F, Guarin E, Nef P, Dubois-Dauphin M (1999) The mouse cpp32 mRNA transcript is early up-regulated in axotomized motoneurons following facial nerve transection. Neurosci Lett 266:65-68.

Deckwerth TL, Elliott JL, Knudson CM, Johnson Jr EM, Snider WD, Korsmeyer SJ (1996) BAX is required for neuronal death after trophic factor deprivation and during development. Neuron 17:401-411.

Du C, Fang M, Li Y, Li L, Wang X (2000) Smac, a mitochondrial protein that promotes cytochrome $c$-dependent caspase activation by eliminating IAP inhibition. Cell 102:33-42.

Dubois-Dauphin M, Frankowski H, Tsujimoto Y, Huarte J, Martinou JC (1994) Neonatal motoneurons overexpressing the bcl-2 protooncogene in transgenic mice are protected from axotomy-induced cell death. Proc Natl Acad Sci USA 91:3309-3313.

Elliott JL, Snider WD (1996) Axotomy-induced motor neuron death. In: Cell death and diseases of the nervous system (Koliatsos VE, Ratan RR, eds), pp 181-196. Totowa, NJ: Humana.

Fong WG, Liston P, Rajcan-Separovic E, St Jean M, Craig C, Korneluk RG (2000) Expression and genetic analysis of XIAP-associated factor 1 (XAF1) in cancer cell lines. Genomics 70:113-122.

Gillardon F, Klimaschewski L, Wickert H, Krajewski S, Reed JC, Zimmermann M (1996) Expression pattern of candidate cell death effector proteins Bax, Bcl-2, Bcl-X, and c-Jun in sensory and motor neurons following sciatic nerve transection in the rat. Brain Res 739:244-250.

Gimenez y Ribotta M, Revah F, Pradier L, Loquet I, Mallet J, Privat A (1997) Prevention of motoneuron death by adenovirus-mediated neurotrophic factors. J Neurosci Res 48:281-285.

Gravel C, Gotz R, Lorrain A, Sendtner M (1997) Adenoviral gene transfer of ciliary neurotrophic factor and brain-derived neurotrophic factor leads to long-term survival of axotomized motor neurons. Nat Med 3:765-770.

Guarin E, Seuret P, Nef S, de Bilbao F, Nef P, Dubois-Dauphin M (1999) cpp32 messenger RNA neosynthesis is induced by fatal axotomy and is not regulated by athanatal Bcl-2 over-expression. Neuroscience 90:653-664.

Leaman DW, Chawla-Sarkar M, Vyas K, Reheman M, Tamai K, Toji S, Borden EC (2002) Identification of X-linked inhibitor of apoptosisassociated factor-1 as an interferon-stimulated gene that augments TRAIL Apo2L-induced apoptosis. J Biol Chem 277:28504-28511.

Li J, Kim JM, Liston P, Li M, Miyazaki T, MacKenzie AE, Korneluk RG, Tsang BK (1998a) Expression of inhibitor of apoptosis proteins (IAPs) in rat granulosa cells during ovarian follicular development and atresia. Endocrinology 139:1321-1328.

Li L, Houenou LJ, Wu W, Lei M, Prevette DM, Oppenheim RW (1998b) Characterization of spinal motoneuron degeneration following different types of peripheral nerve injury in neonatal and adult mice. J Comp Neurol 396:158-168.

Liston P, Roy N, Tamai K, Lefebvre C, Baird S, Cherton-Horvat G, Farahani R, McLean M, Ikeda JE, MacKenzie A, Korneluk RG (1996) Suppression of apoptosis in mammalian cells by NAIP and a related family of IAP genes. Nature 379:349-353.

Liston P, Fong WG, Kelly NL, Toji S, Miyazaki T, Conte D, Tamai K, Craig CG, McBurney MW, Korneluk RG (2001) Identification of XAF1 as an antagonist of XIAP anti-Caspase activity. Nat Cell Biol 3:128-133.

Martin SJ (2002) Destabilizing influences in apoptosis: sowing the seeds of IAP destruction. Cell 109:793-796.

Michaelidis TM, Sendtner M, Cooper JD, Airaksinen MS, Holtmann B, Meyer M, Thoenen H (1996) Inactivation of bcl-2 results in progressive degeneration of motoneurons, sympathetic and sensory neurons during early postnatal development. Neuron 17:75-89.

Namikawa K, Honma M, Abe K, Takeda M, Mansur K, Obata T, Miwa A, Okado H, Kiyama H (2000) Akt/protein kinase B prevents injuryinduced motoneuron death and accelerates axonal regeneration. J Neurosci 20:2875-2886.

Oppenheim RW (1991) Cell death during development of the nervous system. Annu Rev Neurosci 14:453-501.
Palaga T, Osborne B (2002) The 3D's of apoptosis: death degradation and DIAPs. Nat Cell Biol 4:E149-E151.

Parsadanian AS, Cheng Y, Keller-Peck CR, Holtzman DM, Snider WD (1998) Bcl-xL is an antiapoptotic regulator for postnatal CNS neurons. J Neurosci 18:1009-1019.

Perrelet D, Ferri A, MacKenzie AE, Smith GM, Korneluk RG, Liston P, Sagot Y, Terrado J, Monnier D, Kato AC (2000) IAP family proteins delay motoneuron cell death in vivo. Eur J Neurosci 12:2059-2067.

Perrelet D, Ferri A, Liston P, Muzzin P, Korneluk RG, Kato AC (2002) IAPs are essential for GDNF-mediated neuroprotective effects in injured motor neurons in vivo. Nat Cell Biol 4:175-179.

Salveson GS, Duckett CS (2002) IAP proteins: blocking the road to death's door. Nat Rev Mol Cell Biol 3:401-410.

Schweizer U, Gunnersen J, Karch C, Wiese S, Holtmann B, Takeda K, Akira S, Sendtner M (2002) Conditional gene ablation of Stat3 reveals differential signaling requirements for survival of motoneurons during development and after nerve injury in the adult. J Cell Biol 156:287-297.

Senba E, Kaneko T, Mizuno N, Tohyama M (1991) Somato-, branchio- and viscero-motor neurons contain glutaminase-like immunoreactivity. Brain Res Bull 26:85-97.

Srinivasula SM, Gupta S, Datta P, Zhang Z, Hegde R, Cheong N, FernadesAlemri T, Alnemri ES (2003) Inhibitor of apoptosis proteins are substrates for the mitochondrial serine protease Omi/HtrA2. J Biol Chem 278:31469-31472.

Vanderluit JL, McPhail LT, Fernandes KJ, McBride CB, Huguenot C, Roy S, Robertson GS, Nicholson DW, Tetzlaff W (2000) Caspase-3 is activated following axotomy of neonatal facial motoneurons and caspase-3 gene deletion delays axotomy-induced cell death in rodents. Eur J Neurosci 12:3469-3480.

Vaux DL, Silke J (2003) Mammalian mitochondrial IAP binding proteins. Biochem Biophys Res Commun 304:499-504.

Vejsada R, Sagot Y, Kato AC (1995) Quantitative comparison of the transient rescue effects of neurotrophic factors on axotomized motoneurons in vivo. Eur J Neurosci 7:108-115.

Verhagen AM, Vaux DL (2002) Cell death regulation by the mammalian IAP antagonist Diablo/Smac. Apoptosis 7:163-166.

Verhagen AM, Ekert PG, Pakusch M, Silke J, Connolly LM, Reid GE, Moritz RL, Simpson RJ, Vaux DL (2000) Identification of DIABLO, a mammalian protein that promotes apoptosis by binding to and antagonizing IAP proteins. Cell 102:43-53.

Wiese S, Digby MR, Gunnersen JM, Gotz Gunnersen, Pei G, Holtmann B, Lowenthal J, Sendtner M (1999) The anti-apoptotic protein ITA is essential for NGF-mediated survival of embryonic chick neurons. Nat Neurosci 2:978-983.

Xu DG, Korneluk RG, Tamai K, Wigle N, Hakim A, MacKenzie A, Robertson GS (1997a) Distribution of neuronal apoptosis inhibitory protein-like immunoreactivity in the rat central nervous system. J Comp Neurol 382:247-259.

Xu DG, Crocker SJ, Doucet J-P, St-Jean M, Tamai K, Hakim AM, Ikeda J-E, Liston P, Thompson CS, Korneluk RG, MacKenzie A, Robertson GS (1997b) Elevation of neuronal expression of NAIP reduces ischemic damage in the rat hippocampus. Nat Med 3:997-1004.

Xu D, Bureau Y, McIntyre DC, Nicholson DW, Liston P, Zhu Y, Fong WG, Crocker SJ, Korneluk RG, Robertson GS (1999) Attenuation of ischemia-induced cellular and behavioral deficits by X chromosomelinked inhibitor of apoptosis protein overexpression in the rat hippocampus. J Neurosci 19:5026-5033.

Yamamoto Y, Henderson CE (1999) Patterns of programmed cell death in populations of developing spinal motoneurons in chicken, mouse, and rat. Dev Biol 214:60-71.

Yang Q-H, Church-Hajduk R, Ren J, Newton ML, Du C (2003) Omi/HtrA2 catalytic cleavage of inactivates IAPs and facilitates caspase activity in apoptosis. Genes Dev 17:1487-1496.

Yang Y, Yu X (2003) Regulation of apoptosis: the ubiquitous way. FASEB J 17:790-799.

Yang Y, Fang S, Jensen JP, Weissman AM, Ashwell JD (2000) Ubiquitin protein ligase activity of IAPs and their degradation in proteasomes in response to apoptotic stimuli. Science 288:874-877.

Yang YL, Li XM (2000) The IAP family: endogenous caspase inhibitors with multiple biological activities. Cell Res 10:169-177. 